\title{
GAMBARAN PERILAKU REMAJA TERHADAP KEBIASAAN MENGONSUMSI MINUMAN BERALKOHOL DI DESA SAPA KECAMATAN TENGA KABUPATEN MINAHASA SELATAN TAHUN 2012
}

\author{
${ }^{1}$ Raynald A. Issakh \\ ${ }^{2}$ Ronald Ottay \\ ${ }^{2}$ Dina V. Rombot
}

\author{
${ }^{1}$ Kandidat Skripsi Fakultas Kedokteran Universitas Sam Ratulangi Manado \\ ${ }^{2}$ Bagian Ilmu Kedokteran Komunitas Fakultas Kedokteran Universitas Sam Ratulangi \\ Manado \\ Email: pascalavav@gmail.com
}

\begin{abstract}
Alcohol is one of the most widely abused substance in the world. Alcohol use is prevalent in the medical field as a preservative and antiseptic. Alcohol abuse can be bad for our health, and can lead to dependence. Alcoholism is the people who are addicted to alcohol. This study aims to obtain an overview of adolescent behavior in the consumption of alcoholic beverages in the village of Sapa environment II Tenga subdistrict, Minahasa southern disctrict. This study is a descriptive study using a survey method to get an overview of adolescent behavior towards alcohol consumption habits. Results and conclusions: Knowledge: $97.8 \%$ of adolescent know the bad effects of alcohol on health. Attitude: The adolescent agreed participation of the sociality community, parents, religious leaders, and security personnel in the prevention of the abuse of alcoholic beverages. Action: 71 of 93 adolescents admitted to consuming alcoholic beverages.
\end{abstract}

Keywords: alcohol, alcoholism, youth (adolescent), behaviou.

\begin{abstract}
Abstrak: Alkohol merupakan salah satu zat yang paling banyak disalahgunakan diseluruh dunia. Penggunaan alkohol yang lazim pada bidang kedokteran adalah sebagai pengawet dan antiseptik. Penyalahgunaan alkohol dapat berakibat buruk bagi kesehatan, dan dapat menyebabkan ketergantungan. Alkoholisme adalah orang yang kecanduan pada alkohol. Penelitian ini bertujuan memperoleh gambaran umum dari perilaku remaja dalam mengkonsumsi minuman beralkohol di desa Sapa lingkungan II kecamatan Tenga kabupaten Minahasa Selatan. Penelitian ini merupakan penelitian deskriptif dengan menggunakan metode survey untuk mendapatkan gambaran perilaku remaja terhadap kebiasaan mengkonsumsi minuman beralkohol. Hasil dan Simpulan: Pengetahuan: 97,8\% remaja mengetahui dampak buruk minuman beralkohol pada kesehatan. Sikap: Para remaja menyetujui peran serta masyarakat, orang tua, pemuka agama, dan aparat keamanan dalam pencegahan penyalahgunaan minuman beralkohol. Tindakan : 71 dari 93 remaja mengaku mengkonsumsi minuman beralkohol.
\end{abstract}

Kata kunci: alkohol, alkoholisme, remaja, perilaku.

Alkohol merupakan salah satu zat yang banyak disalahgunakan di dunia. Ada tradisi panjang penggunaan zat napza di banyak negara di dunia. Alkoholisme adalah ketergantungan secara fisik maupun mental terhadap alkohol. WHO menyebutkan dampak penyalahgunaan minuman beralkohol berakibat 2,5 juta 
kematian setiap tahun di dunia. 320.000 kematian terjadi pada kelompok berumur antara 15 sampai 20 tahun meninggal dalam kasus yang berhubungan dengan alkohol.1,2 juta kematian pada kelompok umur 21 sampai 39 tahun, dan lebih dari 500.000 kematian yang berhubungan dengan penyalahgunaan alkohol pada kelompok umur. ${ }^{1}$

Alkohol juga merupakan faktor resiko penyakit (hepatitis, gastritis, kanker hati, pankreatitis, hipertensi arterial, penyakit jantung iskemik dan pernyakit neurologis) Amerika pada urutan pertama, dan negaranegara Eropa di urutan kedua.

Di Indonesia terdapat data yang mencatat dari keseluruhan kasus pasien yang dirawat karena ketergantungan obat di Indonesia, 30\% di antaranya merupakan pasien karena kecanduan alkohol, bahkan $50 \%$ dari pelajar sekolah mengaku pernah merasakan minum minuman beralkohol. ${ }^{2}$

Data yang didapatkan dari kepolisian kota Manado tentang kasus yang berhubungan dengan minuman beralkohol mencatat sepanjang tahun 2011 - 2012 di Manado terjadi 33 kasus penganiayaan dan 21 kasus kecelakaan lalu lintas yang disebabkan oleh minuman beralkohol. ${ }^{3}$

Data dari kepolisian kecamatan Tenga mencatat 34 kasus penganiayaan dan 17 kasus kecelakaan lalu lintas sepanjang tahun 2011 sampai dengan 2012 bulan Oktober. $^{4}$

Minuman beralkohol adalah minuman yang mengandung Etanol. Alkohol merupakan zat Khamar, artinya zat yang memabukkan, menyebabkan penurunan kesadaran, dan ketergantungan (adiksi). Minuman beralkohol terbagi atas 3 golongan dilihat dari kadar alkoholnya, yaitu:

- Golongan A : berbagai jenis minuman beralkohol yang mengandung kadar alkohol sekitar 1\%-5\%. Contoh minuman beralkohol ini : Bir, Greensand, Heineken.

- Golongan B : berbagai jenis minuman beralkohol yang mengandung kadar alkohol sekitar
5\%-20\%. Contoh minuman beralkohol ini : Anggur, Malaga, Kasegaran.

- Golongan C : Minuman beralkohol yang mengandung kadar alkohol antara 20\%-50\% yang termasuk jenis ini : Randy, Vodka, Wine, Drum, Champagne, Whisky. ${ }^{8}$

Alkohol merupakan sekelompok senyawa organik. Alkohol absolut (Etanol yang mengandung kurang dari $1 \%$ air) kadang digunakan melalui injeksi untuk meredakan neuralgia trigeminal dan nyeri lain yang sulit ditangani. Etil alkohol (Etanol) adalah minuman alkohol yang mengandung bahan memabukkan. Etanol menguatkan efek hipnotik dan penenang. ${ }^{9}$ Alkohol bersifat mudah menguap karena rentang rantai karbon $\mathrm{C}_{1}$ sampai $\mathrm{C}_{5}$ mempunyai titik didih $0^{\circ} \mathrm{C}-50^{\circ} \mathrm{C}$. Pada saat ini, kadar Etanol paling tinggi yang ada di pasaran adalah $96 \%$ untuk konsentrasi teknis. $^{5}$

Penyalahgunaan alkohol jangka panjang menyebabkan hepatitis, sirosis, hipertensi portal, gastritis, kelebihan muatan zat besi, kanker hati primer, kanker hati lain (mis., kepala dan leher), pankreatitis, hipertensi arterial, penyakit jantung iskemik dan masalah neurologis yang disebabkan toksisitas alkohol atau defisiensi Vitamin B. ${ }^{6}$

\section{METODE PENELITIAN}

Jenis penelitian yang digunakan adalah penelitian bersifat deskriptif dengan pendekatan metode survei. Penelitian ini mengambil tempat di Desa Sapa Lingkungan II Kecamatan Tenga Kabupaten Minahasa Selatan. Populasi pada penelitian ini adalah para remaja berusia 15-20 tahun (kriteria berdasarkan WHO) di Desa Sapa Lingkungan II Kecamatan Tenga Kabupaten Minahasa Selatan, sedangkan sampel pada penelitian ini adalah semua remaja berusia 15-20 tahun yang ada di Desa Sapa Lingkungan II berjumlah 93 orang. Data penelitian diperoleh dengan membagikan kuesioner kepada seluruh sampel untuk di isi agar peneliti memperoleh data penelitian yang 
akan diolah, digolongkan, menggunakan program Microsoft Excel dan ditampilkan dalam bentuk Tabel. ${ }^{7}$

\section{HASIL PENELITIAN DAN BAHASAN}

\section{A. Distribusi berdasarkan Pengetahuan Responden}

Tabel 1. Karakteristik pendidikan responden

\begin{tabular}{ccc}
\hline Pendidikan & $\mathrm{N}$ & $\%$ \\
\hline SMP & 15 & 16,1 \\
SMA & 58 & 62,4 \\
SMK & 12 & 12,9 \\
Perguruan & 8 & 8,6 \\
Tinggi & & \\
\hline Jumlah & 93 & 100 \\
\hline
\end{tabular}

Melihat Tabel diatas, 62,4\% responden berpendidikan SMA, dan 8,6\% responden berpendidikan perguruan tinggi.

Dari Tabel itu dapat dikatakan tingkat pendidikan di Desa Sapa cukup baik. Hal ini disebabkan Jarak sekolah (SD,SMP,SMA) dari Desa Sapa tidak terlalu jauh, sebagian bisa ditempuh dengan berjalan kaki, ataupun dengan sepeda motor. Sedangkan SMK hanya terdapat di kota. Dan tingkat kesadaran masyarakat akan pentingnya pendidikan cukup besar. Namun Sedikitnya remaja yang melanjutkan pendidikan ke perguruan tinggi disebabkan oleh tidak adanya biaya, ataupun kemauan responden itu sendiri yang ingin langsung bekerja.

Tabel 2. Karakteristik pekerjaan responden

\begin{tabular}{ccc}
\hline Pekerjaan & $\mathrm{N}$ & $\%$ \\
\hline Tidak & 22 & 23,8 \\
Bekerja & & \\
Pelajar & 19 & 20,4 \\
Mahasiswa & 8 & 8,6 \\
Swasta & 3 & 3,2 \\
Nelayan & 7 & 7,5 \\
Petani & 9 & 9,7 \\
Pegawai & 12 & 12,9 \\
Bengkel & & \\
Tukang & 13 & 14,0 \\
\hline Jumlah & 93 & 100 \\
\hline
\end{tabular}

Sesuai pada tabel 3 diatas, 23,8\% responden pengangguran, dan 3,2\% responden memiliki pekerjaan swasta.

Setelah peneliti tanyakan, ternyata para responden yang pengangguran dulunya pernah mempunyai pekerjaan. Sebagai tukang ojek, pekerja bangunan, buruh, ataupun pegawai. Namun sebagian besar dari mereka kehilangan pekerjaan karena terlibat keributan di tempat mereka bekerja. Sebagian responden yang peneliti tanyai juga mengaku menjadi malas bekerja, atau mengantuk, karena pada malam harinya sering mengkonsumsi minuman beralkohol.

Tabel 3. Apakah remaja boleh mengkonsumsi minuman beralkohol?

\begin{tabular}{ccc}
\hline Jawaban & $\mathrm{N}$ & \% \\
\hline Ya Boleh & 29 & 31,2 \\
Tidak & 64 & 68,8 \\
Boleh & & \\
\hline Jumlah & 93 & 100 \\
\hline
\end{tabular}

Dapat kita lihat tabel diatas, 68,8\% responden menjawab remaja tidak boleh mengkonsumsi minuman beralkohol, dan $31,2 \%$ menjawab boleh.

Tabel 4. Tahukah anda jika mengkonsumsi minuman beralkohol dalam jumlah yang banyak dapat berdampak buruk pada kesehatan?

\begin{tabular}{ccc}
\hline Jawaban & $\mathrm{N}$ & $\%$ \\
\hline Ya Tahu & 91 & 97,8 \\
Tidak & 2 & 2,2 \\
Tahu & & \\
\hline Jumlah & 93 & 100 \\
\hline
\end{tabular}

Berdasarkan Tabel diatas, 97,8\% responden mengetahui mengkonsumsi minuman beralkohol dapat berdampak buruk untuk kesehatah, dan 2,2\% responden tidak mengetahui.

Dari uraian kuesioner Distribusi berdasarkan pengetahuan responden, dapat kita katakan bahwa pengetahuan remaja di Desa Sapa cukup baik. Hal ini disebabkan oleh tingkat pendidikan yang cukup baik di Desa Sapa, dan banyaknya informasi 
mengenai minuman beralkohol di Desa Sapa.

\section{A. Distribusi berdasarkan sikap responden}

Tabel 5. Peran orang tua dalam pencegahan penyalahgunaan minuman beralkohol

\begin{tabular}{ccc}
\hline Peran & $\mathrm{N}$ & $\%$ \\
Orang tua & & \\
\hline Setuju & 85 & 91,4 \\
Tidak & 8 & 8,6 \\
Setuju & & \\
\hline Jumlah & 93 & 100 \\
\hline
\end{tabular}

Sesuai Tabel 9 diatas, 91,4\% responden setuju terhadap peran orang tua pada pencegahan penyalahgunaan minuman beralkohol, dan 8,6\% responden tidak setuju.

Hal ini dikarenakan orang tua merupakan sosok yang paling penting untuk remaja. Orang tua harus mengontrol dengan baik pergaulan remaja mereka, agar tetap pada pergaulan yang sehat. Walaupun beberapa responden mengaku bahwa orang tua mereka tidak pernah marah pada saat responden tersebut mengkonsumsi minuman beralkohol. Namun peran serta orang tua tetap dianggap yang terpenting dalam mencegah para remaja mengkonsumsi minuman beralkohol.

Tabel 6. Peran masyarakat dalam pencegahan penyalahgunaan minuman beralkohol

\begin{tabular}{ccc}
\hline Peran masyarakat & $\mathrm{N}$ & $\%$ \\
\hline Setuju & 88 & 95,6 \\
Tidak Setuju & 5 & 5,4 \\
\hline Jumlah & 93 & 100 \\
\hline
\end{tabular}

Dapat kita lihat pada diatas, 95,6\% responden setuju terhadap peran masyarakat pada pencegahan penyalahgunaan minuman beralkohol, dan $5,4 \%$ responden tidak setuju.

Hal ini disebabkan peran serta masyarakat di Desa Sapa dalam mencegah penyalahgunaan minuman beralkohol sangat minim. Dapat dilihat dari beberapa masyarakat yang turut serta mengkonsumsi minuman beralkohol bersama para remaja, bahkan tidak jarang mengajak para remaja mengkonsumsi minuman beralkohol bersama-sama. Hal tersebut tentu sangat mendukung para remaja untuk mengkonsumsi minuman beralkohol. Dan sangat disayangkan karena ketidakpedulian masyarakat dalam mencegah penyalahgunaan minuman beralkohol tersebut membuat para remaja tidak segan lagi, dan merasa bebas mengkonsumsi minuman beralkohol di Desa Sapa.

Tabel 7. Peran aparat keamanan dalam pencegahan penyalahgunaan minuman beralkohol

\begin{tabular}{ccc}
\hline Aparat keamanan & $\mathrm{N}$ & $\mathbf{\%}$ \\
\hline Setuju & 82 & 88,2 \\
Tidak Setuju & 11 & 11,8 \\
\hline Jumlah & 93 & 100 \\
\hline
\end{tabular}

Berdasarkan Tabel 11, 88,2\% responden setuju terhadap peran aparat keamanan pada pencegahan penyalahgunaan minuman beralkohol, dan 11,8\% responden tidak setuju.

Di Desa Sapa peneliti tidak menjumpai aparat keamanan Desa, menurut hukum tua Desa Sapa Lingkungan II, hal tersebut dikarenakan, keamanan desa biasanya dijaga bersama-sama warga Desa Sapa lainnya (Lingkungan I dan III), walaupun ada keributan, akan diselesaikan secara kekeluargaan, dan jarang diadukan sampai ke pihak kepolisian. Ketertiban Desa pun tidak dijalankan dengan baik. Tidak diberlakukan jam malam, dan orang-orang yang ditunjuk untuk berjaga malam (ronda) sering kali acuh dan tidak peduli.

Tabel 8. Diadakannya penyuluhan tentang bahaya dan dampak mengkonsumsi minuman beralkohol

\begin{tabular}{ccc}
\hline Penyuluhan & $\mathrm{N}$ & $\%$ \\
\hline Setuju & 91 & 97,8 \\
Tidak & 2 & 2,2 \\
Setuju & & \\
\hline Jumlah & 93 & 100 \\
\hline
\end{tabular}


Sesuai tabel diatas, 97,8\% responden setuju diadakannya penyuluhan tentang bahaya dan dampak dari mengkonsumsi minuman beralkohol, dan 2,2\% tidak setuju.

Di Desa Sapa tidak pernah diadakan penyuluhan tentang minuman beralkohol, oleh sebab itu banyak remaja maupun masyarakat yang mengharapkan diadakannya penyuluhan mengenai bahaya dan dampak mengkonsumsi minuman beralkohol. Hal ini tentunya dapat meningkatkan pemahaman para remaja akan bahaya dan dampak mengkonsumsi minuman beralkohol secara mendalam.

\section{B. Distribusi berdasarkan tindakan responden}

Tabel 9. Apakah anda mengkonsumsi minuman beralkohol?

\begin{tabular}{lll}
\hline $\begin{array}{l}\text { Tindakan } \\
\text { responden }\end{array}$ & $\mathrm{N}$ & $\%$ \\
\hline Ya & 71 & 76,3 \\
Tidak & 22 & 23,7 \\
\hline Jumlah & 93 & 100 \\
\hline
\end{tabular}

Berdasarkan Tabel diatas, terdapat 76,3\% remaja yang mengkonsumsi minuman beralkohol, dan $23,7 \%$ remaja yang tidak mengkonsumsi minuman beralkohol.

Hal ini menunjukkan masih banyak remaja yang mengkonsumsi minuman beralkohol di Desa Sapa meskipun tingkat pengetahuan mereka mengenai bahaya minuman beralkohol cukup baik. Namun Faktor Keluarga, masyarakat, dan aparat keamanan yang kurang peduli membuat remaja merasa bebas mengkonsumsi minuman beralkohol. Ditambah lagi, penjualan minuman beralkohol di Desa Sapa masih sangat bebas.

Tabel 10. Pernah merasa sakit setelah mengkonsumsi minuman beralkohol?

\begin{tabular}{ccc}
\hline Jawaban & $\mathrm{N}$ & $\%$ \\
\hline Ya pernah & 49 & 69 \\
Tidak pernah & 22 & 31 \\
\hline Jumlah & 71 & 100 \\
\hline
\end{tabular}

Berdasarkan Tabel diatas, 69\% responden pernah merasa sakit setelah mengkonsumsi minuman beralkohol, dan 31\% tidak pernah.

Dampak buruk mengkonsumsi minuman beralkohol bagi kesehatan ternyata pernah dirasakan sebagian besar responden. Namun tidak membuat para responden berhenti untuk mengkonsumsi minuman beralkohol.

Tabel 11. Pada situasi seperti apa anda merasa memerlukan minuman beralkohol?

\begin{tabular}{ccc}
\hline $\begin{array}{c}\text { Situasi yang } \\
\text { membutuhkan } \\
\text { minuman }\end{array}$ & $\mathrm{N}$ & $\%$ \\
beralkohol & & \\
\hline $\begin{array}{c}\text { Sendirian } \\
\text { Kumpul bersama } \\
\text { teman } \\
\text { Saat }\end{array}$ & 90 & 12,7 \\
frustasi/stress & 10 & 14,1 \\
Acara/syukuran & 12 & 16,9 \\
\hline Jumlah & 71 & 100 \\
\hline
\end{tabular}

Berdasarkan Tabel diatas, 56,3\% responden menjawab kumpul bersama teman adalah situasi yang paling mendukung untuk mengkonsumsi minuman beralkohol, sedangkan 14,1\% responden menjawab sendirian adalah situasi yang paling mendukung untuk mengkonsumsi minuman beralkohol.

Tabel 12. Cara memperoleh minuman beralkohol

\begin{tabular}{ccc}
\hline $\begin{array}{c}\text { Memperoleh } \\
\text { minuman } \\
\text { beralkohol }\end{array}$ & $\mathrm{N}$ & $\%$ \\
\hline Beli di warung & 51 & 72,8 \\
Di beri teman & 12 & 16,9 \\
Memalak orang & 5 & 7,5 \\
Diberi orang tua & 2 & 2,8 \\
\hline Jumlah & 71 & 100 \\
\hline
\end{tabular}

Hal ini menunjukkan bahwa masih banyak remaja di Desa Sapa yang salah mengikuti pergaulan akibatnya banyak 
yang terjerumus ke hal-hal yang tidak benar seperti mengkonsumsi minuman beralkohol. Mengingat pengaruh pergaulan yang sangat vital bagi perkembangan positif para remaja.

Sesuai dengan persentase tabel 12, dapat dilihat cara memperoleh minuman beralkohol paling besar adalah membeli di warung yang dinyatakan oleh 51 responden dengan presentase $(71,8 \%)$ sedangkan yang paling rendah sebanyak 2 responden (2,8\%) mengaku diberi oleh orang tua.

Hal diatas menunjukkan bahwa masih banyak warung-warung yang menjual minuman beralkohol dengan bebas dan kurangnya pengawasan dari orang tua sehingga para remaja bisa mendapatkan minuman beralkohol dengan mudah. Aparat yang tidak menertibkan para penjual minuman beralkohol juga berperan sangat penting, yang membuat para penjual merasa bebas untuk menjual minuman beralkohol (captikus).

Pergaulan merupakan faktor utama para remaja di desa Sapa untuk mengkonsumsi minuman beralkohol. Sebagian remaja juga menjawab lebih percaya diri, dan mudah untuk bergaul setelah mengkonsumsi minuman beralkohol.

Frekuensi mengkonsumsi minuman beralkohol pada remaja di desa Sapa paling banyak 2x seminggu. Dan minuman yang paling sering dan banyak dikonsumsi adalah "captikus" hal ini karena sangat mudahnya mendapatkan "captikus" tersebut di warung-warung desa.
Kesadaran akan bahaya mengkonsumsi minuman beralkohol di desa Sapa harus disempurnakan, dan dimengerti secara keseluruhan dengan dampak sosial dan medis bagi remaja meskipun memiliki pengetahuan yang cukup dan seringkali terlibat dalam keributan di desa, para remaja masih saja mengkonsumsi minuman beralkohol.

Lingkungan pergaulan yang tidak sehat pun terus mendorong para remaja untuk mengkonsumsi minuman beralkohol, butuh kerja sama yang baik antara orang tua, masyarakat, pemerintah, aparat keamanan, maupun para remaja sendiri untuk menumbuhkan kesadaran diri, dan berhenti mengkonsumsi minuman beralkohol

\section{DAFTAR PUSTAKA}

1. Ingram I.M, Timbury G.C, Mowbray R.M. 2007. Catatan Kuliah Psikiatri Penerbit Buku Kedokteran EGC.

2. Pickett G, Hanlon J.J 2009. Kesehatan Masyarakat Administrasi dan Praktik. Penerbit Buku Kedokteran EGC.

3. Kepolisian Manado. Data Kasus Kriminal yang Berhubungan Dengan Penyalahgunaan Minuman Beralkohol Tahun 2011 - 2012.

4. Kepolisisan Kecamatan Tenga. Data Kasus Kriminal yang Berhubungan Dengan Penyalahgunaan Minuman Beralkohol Tahun 2011 - 2012.

5. Darman. F. 2006. Mengenal Jenis \& Efek Buruk Narkoba. Visimedia.

6. Semiun Y. 2006.Kesehatan Mental 2. Kanisius. 